\title{
Towards Adopting an 'Economic Impact' Approach in the Classification of the Burden of Oral Diseases: The Case of the East African Community Countries
}

\author{
Okemwa, kenneth. $\mathrm{A}^{1}$, Ruttoh ,simon. $\mathrm{K}^{2}$ \\ School of Dentistry, College of Health Sciences, Moi University, Eldoret 4606 30100, Kenya. \\ School of Public Health, College of Health Sciences, Moi University, Eldoret 460630100 , Kenya.
}

\begin{abstract}
\section{$>$ Introduction}

This commentary argues for a change in the way we communicate the burden of dental diseases to policy makers so that the economic impact of these diseases can be more easily and realistically appreciated. Specific reference to dental caries in the East African Community countries (EAC) will be used to argue out the case.
\end{abstract}

\section{$>$ Methods}

A literature review was done to tease out the severity and prevalence of Dental caries in the EAC countries. Using the average DMFT/dmft, the approximate cost which would be required to treat dental caries in each country was calculated.

\section{$>$ Results}

The EAC countries are classified as having very low severity of dental caries among 12 year olds and low severity among adults aged 33-44 years. However the financial implication of treatment of dental caries for each country is enormous.

\section{$>$ Conclusion}

Focus on DMFT alone to convey the burden of dental caries may send wrong messages to policy makers thus affecting oral health financing.

\section{$>$ Recommendations}

A Caries Economic Burden (CEB) index is proposed. This index would quantify the cost of caries treatment in a country by multiplying a country's average DMFT by the population and average cost of treatment. This index will be dynamic and country specific.

Keywords:- dental caries, DMFT, economic impact, East African Community countries, , caries economic burden index $(\boldsymbol{C E B})$

\section{INTRODUCTION}

Reporting the economic burden of oral diseases is important to evaluate the societal relevance of preventing and addressing oral diseases. In addition to treatment costs, there are indirect costs to consider, mainly in terms of productivity losses due to absenteeism from work. The study published in 2015 on global economic burden of dental disease suggests that the economic impact amounted to US\$442 billion in 2010 in both direct and indirect costs, corresponding to an average of $4.6 \%$ of global health expenditure $[1]$

In resource constrained countries, competition for scarce national resources is such that priority would be given to those areas in health perceived, through available data, to be most needy. Measures of morbidity, severity and mortality of diseases and conditions therefore play an important role in decision making by policy makers.

The most commonly used measure of dental caries in populations and individuals is the Decayed; Missing and Filled teeth (DMFT) index for permanent teeth and the $\mathrm{dft}$ (decayed, filled teeth) index for primary teeth.

These indices have been given an explanatory translation as follow:

$\begin{array}{ll}\text { DMFT } & \text { TRANSLATION } \\ <1.1 & \text { very low } \\ 1.2-2.5 & \text { low } \\ 2.6---3.5 & \text { moderate } \\ >3.5 & \text { high }\end{array}$

For policy makers-who, more often than not, happen to be politicians- the terms 'very low' and 'low', 'moderate 'and 'high' are what will be teased out of the classification.

The implication of this is that, most likely, not much priority will be given to dental health care in terms of financial allocation in those countries with a lower rating scale. 
Perhaps then to remedy this scenario, as health care professionals we need to be more ingenious in the way we communicate the burden of oral diseases to policy makers.

It is out of this conviction that this concept paper argues for a classification of the burden of dental caries based on an 'economic impact approach'. This classification would easily bring out the financial implications of dental disease to a country; and perhaps impress upon the policy makers the need for adequate oral health care financing.

The countries of the East African community (Kenya, Uganda, Tanzania, Burundi, and Rwanda) will be used in this discussion. The governments of these countries fund the provision of oral health care to their citizens either fully or in a subsided format. They are therefore the focus of this discussion

\section{The EAC scenario}

According to the World Health Organization ( WHO) global caries map, the East African community countries (EAC) are classified as having very low or low levels of dental caries among 12 year olds based on the DMFT/dft indices (2014 data) ${ }^{[2]}$. A similar map for adults classifies the severity among adults aged 33-44 years as low.

Table 1 below is an extract from the WHO global oral health database on DMFT for 12-year-olds (2015) [3].

\begin{tabular}{|c|c|c|c|}
\hline Country & Year & DMFT & classification \\
\hline Burundi & $1987-1988$ & 1.0 & Very low \\
\hline Kenya & 2015 & 0.4 & Very low \\
\hline Rwanda & 1993 & 0.3 & Very low \\
\hline Tanzania & 2004 & 0.3 & Very low \\
\hline Uganda & 2008 & 0.7 & Very low \\
\hline
\end{tabular}

Table 1:- DMFT information -WHO

This puts across the message that dental caries is very low in these countries; and from a policy point of view this may not attract much concern.

\section{Cost translation of DMFT for EAC and implication on country health budgets}

The Kenya Medical Practitioners and Dentist Board (KMPDB) has guidelines on the cost of dental treatment in Kenya [4]. Though these apply to private practice it is assumed that these constitute the actual cost even in the government hospitals since the government covers the subsidised cost through equipment supply, remuneration and training of health care workers.

Online search did not elicit similar cost guidelines from the other 4 countries. The KMPDB fee guideline will therefore be used as the average cost across the EAC countries.

For resource constrained countries, it is most likely that the treatment prescribed for dental caries, at least at its symptomatic stage, is extraction or filling. The other treatment options like endondotic treatment and crowns tend to be out of reach for most people. As a result, the costs of simple extraction and fillings will be used in this discussion.

For the purposes of this paper the average cost of treatment of a decayed tooth will be taken as the average of the sum cost of an extraction (ksh 3000) and that of a filling (kshs 4000). The lower cost for each procedure has been taken. Therefore the average cost for purposes of this write-up will be KSh 3500 -about 35 United States dollars (USD) currently. The cost of other more expensive forms of treatment like root canal treatment and crowns will not be considered for the purpose of this paper. This is because. In 2015 the ministry of health in Kenya undertook the first national oral health survey which indicate an overall DMFT for adults of 0.72 and an overall DMFT/dft of 0.72 for children aged 5,12 and 15 years respectively $\underline{5}$.

A similar survey done in Rwanda in 2018 indicated dft of 1.69 and DMFT of 3.196

Since this is the data most likely to be considered by policy makers it will be used to argue the concept in this discussion for Kenya and Rwanda. The other 3 countries don't seem to have done national oral health surveys therefore the figures available from WHO will be used.

For Tanzania the average of the dft and DMFT from the study done by Carneiro et al in 2012 will be used since this is the latest information which seems to be available online. The dft from this study was 0.95 while the DMFT was 1.26 thus giving an average of 1.17

Latest study published from Uganda in 2015 gave an overall dft of 0.73 and DMFT of 4.71 . The average of these values $(2.72)$ will be used $\stackrel{8}{\text {. }}$

There are no current studies which have been done in Burundi therefore the figure available on the WHO website will be used.

Based on these figures, Table 2 below illustrates the potential financial cost- equivalent for treatment which each country would incur. 
ISSN No:-2456-2165

\begin{tabular}{|c|c|c|c|c|c|}
\hline Country & averageDMFT/dft & $\begin{array}{c}\text { Population } \\
(000,000) \\
(2017)^{9}\end{array}$ & $\begin{array}{c}\text { Gross number of } \\
\text { Carious teeth }\end{array}$ & $\begin{array}{c}\text { App cost of treatment } \\
\text { needed (millions of US } \\
\text { Dollars) }\end{array}$ & $\begin{array}{c}\text { Budget allocation for } \\
\text { health per country } \\
\text { (million US dollars) } \\
\text { 2017-2018 }\end{array}$ \\
\hline Kenya & 0.73 & 49.70 & $32,375,500$ & 1133 & $1^{1236^{\underline{1}}}$ \\
\hline Rwanda & 2.94 & 12.21 & $35,897,400$ & 1256 & $202 \mathrm{M}^{11}$ \\
\hline Tanzania & 1.1 & 57.31 & $63,041,000$ & 2206 & $961 \mathrm{M}^{\frac{12}{13}}$ \\
\hline Uganda & 2.72 & 42.86 & 116579200 & 1095 & $493 \mathrm{M}^{\underline{13}}$ \\
\hline Burundi & 1.0 & 10.86 & $10,860,000$ & 380 & $91^{\underline{14}}$ \\
\hline
\end{tabular}

Gross number of carious teeth=DMF/df $X$ population: cost=number of carious teeth $X$ USD 35:

Table 2:- Country specific DMFT/dft cost implication

It is apparent that the amount of money which would be required to treat this "low" occurrence of dental caries in these countries is quite substantial- surpassing the total budgetary allocation for health in all the countries. In Kenya alone this would add up to USD 113 MILLION; almost equivalent to the total budgetary allocation for Health at National and county government levels for the year 2016/2017. Treatment costs for Rwanda, Tanzania, Uganda and Burundi would be 6, 2.3, 2.2 and 4 times more than those countries' health budgets respectively.

\section{Suggested approach}

Based on the most recent surveys in a country, a table can be formulated where the DMFT and dft values for that country are translated into an economic burden equivalent for that country using the formula:

DMFT $x$ AVERAGE COST OF TREATMENT IN USD $\times$ POPULATION= total cost to country needed for dental caries treatment in USD

Caries Economic Burden $($ CEB $)$ index $=$ total cost above/1000000

The CEB for the East African countries ,as derived from table 3, would therefore be 1133, 1256, 2206 , 1095 and 380 for Kenya, Rwanda, Tanzania , Uganda and Burundi, respectively.

The CEB X 1000000 will be the total cost, in United State dollars, which a country would need to treat its population of dental caries in the year under consideration.

\section{Characteristics of this proposed index include}

- Flexibility and country specificity so as to take into consideration the economic status for each country. This will be in line with with the FDI recommendations in the GLOBAL ORAL HEALTH GOALS 2020 where the motto: 'think globally act locally'' is advocated(5) $\underline{15}$

- Dynamism which takes into consideration the projected yearly increase in population of that country. This means that it will be reviewed periodically (annually, biannually or otherwise) depending on the actual or projected population changes). Dynamism would also mean a recalculation wherever there is new data from research

\section{$>$ Weakness of the discussion}

The definition of economic burden in our discussion is purely based on the direct cost of treatment and excludes the indirect costs which are used in already established methodologies.

Our discussion is based on an assumption that the D in the DMFT requires filling or extraction. This of course is another weakness of our debate.

The suggested CEB is very simplistic in nature and has not taken into consideration the indirect costs of dental caries treatment. This of course is an obvious weakness which should always be stated. Given the complexity of calculating indirect cost of illness- and the fact that this is especially so for dental caries, the authors believe that the CEB suggested will be a useful and quick appraisal of a country's dental caries economic burden based on treatment needs

\section{CONCLUSION}

This discussion does not aim to come up with a comprehensive methodology of calculating cost of illness. The CEB suggested rides on the already routine and traditional DMFT classification. It is, so to speak, a conversion of a country's dental caries severity into a cost value.

It is hoped that this paper will trigger off further discussions and debate on the suggestions proposed. Modifications on the proposed index, or indeed an entirely new one, will hopefully arise from this initiative. As earlier stated, sometimes scientific communication may not register in the minds of policy makers with the desired impact, especially at the crucial level of resource allocation. More often than not these are politicians; therefore, it is important that we change the way we communicate to them. This is especially true for resource constrained developing countries like the East African Community countries used in this concept paper.

This should be a dynamic index which is reviewed periodically (annually, biannual or otherwise) depending on projected population changes. Continuous country wide surveys of DMFT will be an important component of the index. 
This suggested classification could also play an important role in arguing for resource allocation for primary oral health care: If policy makers see what can be saved by investing in disease prevention then they are more likely to support primary healthcare budgets which, in the long term, are lower than curative budgets.

\author{
$>$ Abbreviations \\ WHO-World Health Organization \\ DMFT-Decayed, Missing, Filled Teeth index \\ dft- decayed, filled teeth index \\ CEB-Caries Economic Burden index (proposed) \\ EAC- East African Community
}

\section{$>$ Declarations}

- Funding

No funding was obtained for this study

\section{- Author's contributions}

KO came up with the concept and wrote the first draft of the manuscript. RS contributed to the manuscript drafting and modification. Both authors read and approved the final manuscript.

\section{- Ethics approval and consent to participate}

Not Applicable. This is a commentary and did not involve any research therefore a review by the institutional ethics body was not necessary.

\section{- Consent for Publication}

Not applicable

\section{- Competing interests} interests

The authors declare that they have no competing

\section{REFERENCES}

[1]. Listl S, Galloway J, Mossey PA, et al. Global Economic Impact of Dental Diseases. J Dent Res. 2015; DOI: $10.1177 / 0022034515602879$

[2]. Malmo University. Global caries map for 12 year olds. 2014 https://www.mah.se/CAPP/Country-OralHealth-Profiles/According-to-WHO-Regions/Globalcaries-map-2013--2014/ ( Accessed $21^{\text {st }}$ Nov 2019)

[3]. Malmo University. Oral health database. https://www.mah.se/CAPP/Country-Oral-HealthProfiles/AFRO/. (Accessed $21^{\text {st }}$ Nov 2019)

[4]. Government of Kenya, Ministry of Health, Kenya Medical Practitioners and Dentist Board. FEES GUIDELINES FOR MEDICAL \& DENTAL RACTITIONERS. 2016 http://medicalboard.co.ke/resources/Medical_and_De ntal_Professional_Fees_2016.pdf (Accessed on $1^{\text {st }}$ Nov 2019)

[5]. Government of Kenya, Ministry of Health: KENYA NATIONAL ORAL HEALTH SURVEY REPORT 2015. https://profiles.uonbi.ac.ke/gathece/files/kenya_nation al_oral_health_survey_report2015.pdf\&gt

Accessed on $21^{\text {st }}$ Nov 2019)

[6]. Morgan JP, Isyagi M, Ntaganira J, et al. Building oral health research infrastructure: the first national oral health survey of Rwanda. Glob Health Action. 2018;11(1):1477249.

. doi: 10.1080/16549716.2018.1477249

[7]. Carneiro LC, Kabulwa MN. Dental Caries, and Supragingival Plaque and Calculus among Students, Tanga, Tanzania. ISRN Dent. 2012;2012:245296. doi: 10.5402/2012/245296.

[8]. Kutesa A, Kasangaki A, Nkamba M, et al. Prevalence and factors associated with dental caries among children and adults in selected districts in Uganda. Afr Health Sci. $2015 ; 15(4): 1302-7$. doi: 10.4314/ahs.v15i4.33

[9]. World Bank 2017: world population estimates https://data.worldbank.org/indicator/SP.POP.TOTL?lo cations=NG-BI\&name_desc=false

[10]. Republic of Kenya. National and County Health $\begin{array}{lllr}\text { Budget Analysis } & \text { FY 2016/2017. }\end{array}$ http://www.healthpolicyplus.com/ns/pubs/61386239_FINALNationalandCountyHealthBudgetAnalys is.pdf. (Accessed on $14^{\text {th }}$ Feb 2019)

[11]. Ministry of Finance and Economic Planning, Rwanda. The National Budget Citizens' Guide for 2018/2019. http://www.minecofin.gov.rw/fileadmin/templates/doc uments/Fiscal_Decentralisation_Unit/Budget_Citizen _Guide/2018-

2019/2018_19_Final_Citizen_Guide_to_the_Budget__English.pdf (Accessed on $2^{\text {nd }}$ Feb 2019)

[12]. Lee B, Tarimo K. Analysis of the government of Tanzania's budget allocation to the health sector for fiscal year 2017/18'. HP+ policy brief. Washington, DC: Health Policy Plus. http://www.healthpolicyplus.com/ns/pubs/71837323_TanzaniaBudgetAllocationHealthSectorBrief.pd f (accessed on 21st Nov 1019)

[13]. Moses O. The 2017/18 Uganda budget -what is in for the poorest and most vulnerable. Development initiatives. $\quad \mathrm{http}: / /$ devinit.org/wpcontent/uploads/2017/11/the-2017-18-Ugandabudget_briefing-paper.pdf. (Accessed on 25 $5^{\text {th }}$ Jan 2019.)

[14]. UNICEF. The 2017 State Budget, Burundi. https://www.unicef.org/esa/sites/unicef.org.esa/files/2 018-09/UNICEF-Burundi-2017-National-BudgetBrief.pdf (accessed on $25^{\text {th }}$ Jan 2019)

[15]. Hobdell M, Petersen PE, Clarkson J, Johnson N. Global goals for oral health 2020. Int Dent J. 2003;53(5):285-8. 595x.2003.tb00761.x 